\title{
Building Critical Inquiry in the Online EdD: Examining Successes \& Challenges
}

\author{
Eric Ludwig \\ Florida State University \\ eludwig@fsu.edu \\ Courtney Preston \\ Florida State University \\ cpreston@fsu.edu
}

\begin{abstract}
In this essay, we apply Garrison et al.'s $(2000,2003)$ framework for critical inquiry in online learning to a review of a cohort-based online EdD at a large public research-intensive university. We examine the technological, pedagogical, and organizational successes and challenges we have experienced and encounter in building and sustaining critical inquiry in a fully online doctoral program. Includes considerations for faculty and administrators in developing and managing online $\mathrm{EdD}$ programs committed to engaging in critical inquiry and reflection.
\end{abstract}

KEYWORDS

critical inquiry, online learning, online EdD, education doctorate

\section{INTRODUCTION}

Online learning is not new to higher education in the United States. Colleges and universities across the country have been offering individual courses and degree programs at a distance and through computer-mediated and digital technologies for the better part of the 21st Century (Moore \& Kearsley, 2011; Saba, 2011; Simpson \& Anderson, 2012). Before the personal computer and internet made synchronous and asynchronous online learning a possibility for millions of students, institutions offered coursework at a distance to local and regional communities through correspondence courses and other non-computer mediated means (Saba, 2011; Sumner, 2000).

But, over the last decade, the number of students participating in exclusively online academic programs has increased markedly (Seaman et al., 2018). While undergraduate students have been responsible for the lion's share of that growth, graduate and professional students have also been enrolling in online programs with increasing frequency. In 2018, nearly a third of all graduate students (31\%) -- and $25 \%$ at public institutions -- were enrolled in academic programs offered exclusively at a distance (NCES, 2020). A cursory glance at new and existing graduate programs offering exclusively online coursework provides a confirmation of this trend. Whether as a means to generate new revenue or as a response to student demand (or, more likely, a combination of both), colleges and universities have created new programs and modified existing offerings that can be completed entirely online (Blagg, 2018). Indeed,

New articles in this journal are licensed under a Creative Commons Attribution 4.0 United States License. this issue itself is dedicated to the Online EdD; of the current Carnegie Project on the Education Doctorate (CPED) member institutions, a significant number of EdD programs are offered exclusively or almost exclusively online (i.e., with the exception of minor residency requirements).

Given the apparent growth of online EdD programs over the last decade, we, as educators, practitioners, and scholars, must continue to explore ways to improve how we teach, interact, and learn in an environment mediated exclusively by synchronous and asynchronous communication technologies, digital tools, and virtual platforms. In this essay, we return to Garrison et al.'s $(2000,2003)$ concept of practical and critical inquiry in distance education. Using their Community of Inquiry (Col) model, Garrison et al. $(2000,2003)$ considered how to encourage and sustain critical and reflective thinking in computer-mediated learning environments.

In keeping with their framework of critical inquiry (Garrison et al., 2000, 2003), we explore the technological, pedagogical, and organizational successes and challenges for the online EdD program at Florida State University (FSU). More specifically, we examine how faculty at FSU have worked to design, build, and improve the curriculum, instruction, and experiences within our online EdD program to foster a "dynamic relationship between personal meaning and shared understanding" (Garrison et al., 2000, p. 98). the Education Doctorate: A Knowledge Forum on the EdD (CPED) cpedinitiative.org 


\section{CRITICAL INQUIRY IN DISTANCE EDUCATION}

Garrison and colleagues (2000) suggested that teaching and learning designed for computer-mediated environments did not necessarily guarantee the sort of deep and meaningful "thinking and acting" that "are essential to the educational process" (p. 98). Indeed, they argued for a departure from prior models of distance education as independent and self-directed toward one that was communal, collaborative, and dynamic (Garrison et al., 2003). Their Community of Inquiry (Col) framework is built on this assumption, that students would experience and engage in more critical, more reflective, more meaningful thinking when participating in "collaborative, constructivist learning within a community of learners" (Garrison et al., 2003, p. 115).

In expanding on their original framework, Garrison et al. (2000, 2003) proposed additional strategies for fostering critical thinking and engagement within each of the "three overlapping elements" of the Col model (2003, p. 115). Those elements - teaching presence, social presence, and cognitive presence - represent interconnected domains within which the experience of teaching and learning online occurs. Inside of each "presence," we can design, build, and facilitate learning and interaction that creates "an educational community of inquiry" and expects "critical reflection and discourse" (Garrison et al., 2000, p. 103).

In subsequent work on critical inquiry, Garrison et al. (2003) discussed issues that might hinder critical inquiry within online or computer-mediated learning environments. They classified those issues as technological, pedagogical, or organizational. In the remainder of this essay, utilizing Garrison et al.'s $(2000,2003)$ conceptual framework, we will highlight some of the successes and challenges that we face in building, delivering, and maintaining critical inquiry in the experiences of our online EdD students at Florida State University.

\section{Our Program}

Florida State University's online Doctor of Education in Education Leadership and Policy program is a 3-year cohort-based program that culminates in the completion of a Dissertation in Practice (DIP) that aims to address a problem of practice in a specific local context. During the first two years of the program, students complete coursework in three strands 1) foundations/ policy, 2) methodological approaches, and 3) intensive academic immersion experiences. The intensive academic immersion experiences are focused on refining students' problems of practice and developing components of the DIP. Every summer, students come to campus for a three-day intensive face-to-face institute that complements their coursework and DIP development.

\section{TECHNOLOGICAL SUCCESSES AND CHALLENGES}

Garrison et al. (2003) draw on Bruce and Levin's (1997) taxonomy of educational technologies to highlight potential technological issues that might constrain the organic development of critical inquiry in distance or online learning environments. In defining technologies as a form of media, Bruce and Levin (1997) considered "the ways that they alter the environments for thinking, communicating, and acting in the world" (p. 82). They organized those "mediative" technologies into four different categories: technologies for inquiry, technologies for communication, technologies for construction, and technologies for expression. Within the FSU Online EdD program, we intentionally incorporate a variety of technologies for inquiry, communication, construction, and expression in our program.

\section{Successes}

Within the FSU online EdD program, we rely on a number of technologies, both within and outside of the learning management system (LMS), to engage with students, encourage peer-to-peer collaboration, and foster critical inquiry. In our introductory seminar for new EdD students, they complete a number of asynchronous discussions (communication) in which they collectively examine the big questions around the purposes of education, education reform, and educational policy. In that same course, students later work in small groups to collect and review peer-reviewed journal articles related to their problems of practice and create a collaborative annotated bibliography (inquiry, construction, communication). Throughout their first semester in the program, students meet synchronously with their instructor for individual meetings (communication) and are also introduced to various academic services and student supports at the institution through a series of synchronous $Q \& A$ sessions with university representatives.

As faculty, we aim to leave robust and timely feedback for our students through the scaffolded and embedded assignments that lead to the completion of their Dissertation in Practice (DiP). Feedback does not have to be limited to writing; we also provide recorded audio and video feedback and regularly schedule follow-up meetings with students for further discussion on our feedback (communication). Throughout the program, students have regular opportunities to use technologies for expression; in our Introduction to Qualitative Methods course, students use the introduction to tell a story about themselves using audio, video, or static media (i.e., an image). In that same course, students have the option of creating a visual artifact or recording a video presentation to review a foundational qualitative methodology.

At its core, success in this virtual medium requires special care and attention to the technologies we are integrating into our courses and how students are using them. While asynchronous discussion boards seem quite antiquated as a form of interaction, not all asynchronous conversations are made the same. We have worked as a faculty to rethink not only the prompts that are supposed to drive student discussions, but also to consider the frequency, organization, and purpose of those activities. This might include paring back the number of asynchronous discussions in a course, more clearly linking those discussions to overarching course assessments or projects (construction), restructuring discussions as learning communities or reading groups with clearer outcomes and expectations for engagement (inquiry, construction), and offering student groups the choice to meet and record their conversation synchronously in lieu of the traditional asynchronous comment and response interaction (communication).

Individual and peer-to-peer communication and expression drive how we incorporate digital technologies and influence how we think about course design. But instructor-to-student (in both directions) communication and expression remain vitally important. Some faculty have utilized integrated scheduling software (e.g., Calendly) to allow students to more easily schedule individual meetings at times that work for them. Students can specify whether 
they would prefer to meet synchronously or via phone, attach documents or leave comments prior to the meeting, and receive an invitation with additional meeting details after submitting their request. Although this sort of student-driven scheduling does present its own challenges (e.g., setting clear boundaries around when faculty are and are not available), it also offers opportunities to streamline communication between students and instructors and to facilitate more regular one-to-one interaction. While conducting individual meetings with students can be time-consuming and perpetual work, we have found that one-to-one interaction to be invaluable to building relationships and rapport with individual students across a cohort and throughout a program.

\section{Challenges}

For better or for worse, the majority of the instruction within the FSU online EdD program occurs within the virtual space of a learning management system (LMS). The LMS inherently offers opportunities for clear organization and structure, for uniformity of experience across multiple courses, and for institutional control and security (Pomerantz et al., 2018). But, as others have argued (see, e.g., Kim, 2018; Watters, 2014), the LMS is limiting in its own right; it constrains how we think about, design, and facilitate learning. As a closed system, the LMS tends to not operate seamlessly with the open web (Feldstein, 2017); faculty are often reliant on university staff and administrators to make significant changes to the environment or to integrate new or existing technologies into their instruction. These restrictions often funnel exploration and experimentation into a narrow lane of possibilities that must meet institutional requirements and expectations.

More practically, the proliferation of platforms and technologies for inquiry (e.g., data access, file storage), communication (e.g., synchronous conferencing, asynchronous chat, collaborative file creation, social media), and expression (e.g., static and multimedia creation, editing, and sharing) means that faculty and students must sift through, agree upon, and become familiar with a range of digital platforms and software applications. EdD students may be using one LMS in their professional workplace yet expected to learn in a different environment within our program. Faculty and students might have used a particular technology in the past, but that tool or platform is obsolete or no longer supported by the institution. Small things, like a mid-semester update to a software application or lack of storage space for recorded video lectures or data, create headaches. Moreover, technologies in and of themselves are not value neutral; digital platforms, applications, and services often rely on and profit from the extraction and commodification of student data and the erosion of user privacy (Gardner, 2019; Gilliard, 2017; Raths, 2018)

Additionally, many of our EdD students work in K12 districts and in colleges and universities in which they may encounter different learning or educational technologies in their daily work. Whether it is a different learning management system or file sharing and creation platform, our students are often working across multiple platforms on multiple machines. While many of these tools and technologies have similar baseline functionalities, students must still learn, navigate, and manage professional and academic work across a variety of digital systems and applications. While we may desire to be innovative or creative in the tools that we use or the manner in which we design our courses, we must also remember that our students have to make sense of those virtual spaces that we build and must be able to use the digital platforms and technologies that undergird those experiences.

\section{PEDAGOGICAL SUCCESSES AND CHALLENGES}

As Garrison et al. (2003) remind us, "the simple adoption of technology does not resolve issues related to the teaching of critical thinking and metacognitive understanding" (p. 122). We have to design and structure our program - and the underlying courses, assessments, and activities - with those goals in mind. In examining the pedagogical successes and challenges of our own program, it might be helpful to return to those three elements at the center of the Community of Inquiry model: teaching presence, social presence, and cognitive presence (Garrison et al., 2000).

\section{Successes}

The FSU Online EdD is a cohort-based program, with roughly 30-40 students admitted in a new cohort each summer term. Typically, those students would meet face-to-face for an intensive 3day experience in Tallahassee during their first (and subsequent) summers in the program. Although this face-to-face requirement falls outside of the conceptual bounds of the Col framework, we believe that it is an important formative experience for new students' socialization and orientation to doctoral education. This experience establishes the foundations of teaching and social presence meaningful connections between faculty and students and among students themselves - so vital to later success and engagement in online coursework (Garrison \& Arbaugh, 2007).

Outside of the intensive face-to-face summer workshop, we see teacher and social presence encouraged through regular synchronous and asynchronous communication. As we mention in the preceding section, faculty regularly meet with students individually within and outside of courses, whether that is the instructor meeting to discuss feedback on an assignment or a major professor meeting with a student to discuss revisions to their DiP. They send weekly announcements and create video tutorials to keep students aware of what they should be doing and learning. Within the individual cohorts, students regularly communicate across their group using asynchronous chat platforms (e.g., GroupMe) to ask questions, share ideas, and connect personally. In their coursework, students work together in small groups, like Reading Groups or Learning Communities, to complete collaborative projects. In our redesigned Qualitative Data Analysis course, students participate in and complete a group data analysis project in which they analyzed how educational leaders described and explained state and institutional policy school re-opening policies amid the COVID-19 pandemic.

Improving cognitive presence across the curriculum was one of the key drivers of our program redesign. Students now complete the majority of the first 3 chapters of their Dissertation in Practice (DiP) through assignments embedded into their first two years of coursework. Assessments and activities are carefully scaffolded to build the skills, knowledge, and critical reflection necessary to prepare students to be successful when working on those embedded assignments. Students have multiple checkpoints with instructors and program faculty along the way to receive formative feedback and have further discussions about the direction of their research. Finally, given the focus of the EdD on training scholar practitioners, we 
endeavor to consistently connect the curriculum and experiences to the work that students do professionally. This might include multiple opportunities for reflection, outlets for professional growth and networking, or collaboratively analyzing and critiquing scholarship related to their own DiP. In their third semester, students complete an audit of their local context and collect information and data relevant to their proposed study and research questions; they also interview key experts who have a deep understanding of or experience with their problem of practice. Additionally, students now can choose elective coursework that is more clearly tailored to their practice and professional aspirations (i.e., coursework more clearly related to K12 policy or higher education policy) and they also have the opportunity to complete additional integrated certificates (i.e., program evaluation or institutional research) to further supplement their skills and experiences.

\section{Challenges}

Faculty from across the Department of Educational Leadership and Policy Studies (ELPS) teach in the online EdD program. This collaborative approach exposes students to multiple perspectives, areas of scholarly and instructional expertise, and pedagogical approaches. However, those faculty do not necessarily all have the same comfort or familiarity with designing online courses and teaching online. As a program, we must continue to explore paths to supporting faculty across our College in designing dynamic, accessible, engaging, and usable online courses. Beyond course design, we need to regularly evaluate the strengths and weaknesses in how our own curriculum and instruction encourages (or discourages) critical inquiry across the EdD program. Teaching online requires more frequent interaction with students in order to create and maintain social presence.

Further, as our students work full time, these interactions may need to occur outside of the typical 9-5 workday and with advanced notice. These are adjustments faculty have had to consider as they work with the online EdD program. For example, we need to consider how we can schedule and organize virtual defenses for university milestones (e.g., a diagnostic exam) that do not require students to upend their professional or personal schedules with little notice. This might require that we open up more evenings (and, potentially, weekends) for synchronous interaction and engagement. This might imply less immediate temporal flexibility or a shifting of availability for faculty, but that might be a reductive conceptualization of how faculty working in exclusively online $\mathrm{EdD}$ and professional graduate programs might alter the structure and rhythm of their own work. Improving the student experience and fostering a more flexible and accessible learning environment for students might require rethinking how and when we work as instructors to be more aligned with the expectations and needs of our students.

Although we promote and champion the flexibility of the program for working adults, we must be aware of how individual students' situations, backgrounds, and prior experiences shape their experiences within our program. Students are juggling not only their professional responsibilities, but also their personal lives and obligations. In certain courses, we have started to offer students more choice in how they might complete select individual or group assignments and, across the program, faculty have tried, especially during the pandemic, to be more understanding and malleable with deadlines and due dates. This work needs to continue beyond the end of the pandemic.
We are not the only online or graduate program that faces these challenges. We understand the time-intensive nature of teaching online, specifically when providing targeted and meaningful feedback and timely support for students in their work (Kebritchi et al., 2017). This is even more critical in a writing-intensive doctoral program with formative and summative Dissertation in Practice (DiP) assignments embedded throughout the curriculum; students rely on clear, thorough, and timely feedback to improve their own thinking and writing. It is an iterative process that is foundational to Garrison et al.'s $(2000,2003)$ idea of critical inquiry in distance learning.

\section{ORGANIZATIONAL SUCCESSES AND CHALLENGES}

When Garrison et al. (2003) originally considered this framework, distance learning did not quite have the strategic importance and institutional acceptance that it does in 2021. However, given the economic and ideological pressures facing higher education, their words still hold a kernel of truth: "online learning presents a crisis situation, in the classic sense of being both an opportunity and a threat" (p. 123). Developing and expanding exclusively online programs is a key institutional enrollment strategy. But, after the rise and fall of the MOOC and similar discussions of technological disruption within higher education, we appear to have agreed upon online learning simply as a different instructional mode - with its own benefits, challenges, and limitations; with its own good and bad - rather than as something that might upend the brick-andmortar foundations of higher education.

This does not imply that there are not organizational constraints that we, as an online EdD program, must confront within our department, college, and university. Faculty from across the Department of Educational Leadership and Policy Studies teach in the online EdD program at FSU. Our students learn from expert scholars and skilled practitioners with advanced knowledge and professional experience in a variety of contexts and institutional settings across the educational landscape. However, many faculty who teach in the online EdD also have responsibilities and obligations to their own programs, which can present challenges to coordination and collaboration with curriculum, advising, and decision-making. Our faculty, like many across higher education and not unlike those students with whom we work every day, are also juggling their personal and professional obligations and managing competing responsibilities and lofty expectations in their own academic lives.

We must be acutely aware of policies, processes, and technologies that reinforce inequity and injustice in our curriculum and in our online spaces. However, we must also recognize those constraints that have largely been subsumed into broader institutional politics, policy, and decision-making beyond our control, recentering our focus on that which we can control.

For example, graduate school or institutional policies might misunderstand or not fully capture how the structure, content, and purpose of the EdD dissertation differs from its $\mathrm{PhD}$ counterpart and how the institution might account for those differences in a way that encourages innovation and creativity in program design and organization. This misapplication of institutional policy to the EdD has cascading effects for our students, faculty, and program writ large. Although CPED has worked tirelessly to promote and advance the cause of the EdD as a degree capable of standing on its own, we 
still must confront beliefs and policies - and the implications of those beliefs and policies - that do not consider and value the unique nature and purpose of the EdD as a degree for scholarly practitioners.

\section{IMPLICATIONS \& CONCLUSION}

In ways that we never expected, building and growing our online EdD program, the only program in our department in which all tenure-track faculty advise students, has served as a catalyst to reexamine our curriculum, our advising, and our focus on equity and inclusion. Thus, our work in this relatively new program, the first online doctoral program at Florida State University, has served to refocus our faculty on the "dynamic relationship between personal meaning and shared understanding" (Garrison et al., 2000, p. 98) in ways that impact students across our program and department.

Simplicity and consistency in design and empathy and presence in our instruction should still drive how we think about the technologies that shape our interactions and communication with students, the pedagogies that influence our curriculum and instruction, and the organizational structures and policies that uphold and support our work with each other and with our students. Working towards those concepts might necessarily require that we reexamine some of our assumptions and expectations about how and when we do the work of teaching, but that reflection - and the subsequent action - should create virtual spaces and environments where students can better do the learning we expect of scholarly practitioners in pursuit of a doctorate of education.

Both students and faculty have different experiences, expectations, levels of comfort with, and access to the digital technologies and virtual environments that we use to foster critical inquiry in the online environment. Going forward, our challenge and charge as an EdD program working with scholarly practitioners is to continue to critically examine and build our program into one that consistently aligns with our values and is constantly striving to be equitable, humane, and empowering.

\section{REFERENCES}

Blagg, K. (2018). The rise of master's degrees: Master's programs are increasingly diverse and online. Urban Institute. https://www.urban.org/ sites/default/files/publication/99501/the_rise_of_masters_degrees_1.pdf

Bruce, B. C., \& Levin, J. A. (1997). Educational technology: Media for inquiry, communication, construction, and expression. Journal of Educational Computing Research, 17(1), 79-102.

Feldstein, M. (2017). What is the next generation? Educause Review, 52 (4). https://er.educause.edu/articles/2017/7/what-is-the-next-generation

Gardner, L. (2019). Students under surveillance? Data-tracking enters a provocative new phase. The Chronicle of Higher Education. https://www. chronicle.com/article/Students-Under-Surveillance-/247312

Garrison, D. R., Anderson, T., \& Archer, W. (2000). Critical inquiry in a textbased environment: Computer conferencing in higher education. The Internet and Higher Education, 2(2-3), 87-105.

Garrison, D. R., \& Arbaugh, J. B. (2007). Researching the community of inquiry framework: Review, issues, and future directions. The Internet and Higher Education, 10(3), 157-172.

Garrison, D. R., Archer, W., \& Anderson, T. (2003). A theory of critical inquiry in online distance education. In M. Moore \& G. Anderson (Eds.), Handbook of Distance Education (pp. 113-127). Erlbaum.

Gilliard, C. (2017). Pedagogy and the logic of platforms. Educause Review, 52(4). https://er.educause.edu/articles/2017/7/pedagogy-and-the-logicof-platforms
Kebritchi, M., Lipschuetz, A., \& Santiague, L. (2017). Issues and challenges for teaching successful online courses in higher education: A literature review. Journal of Educational Technology Systems, 46(1), 4-29.

Kim, J. (2018). 5 ways I got the future of the LMS wrong. Inside Higher Ed. https://www.insidehighered.com/digital-learning/blogs/technology-andlearning/5-ways-i-got-future-Ims-wrong

Moore, M. G., \& Kearsley, G. (2011). Distance education: A systems view of online learning (3rd ed.). Cengage Learning.

National Center for Education Statistics (NCES) (2020). The condition of education: Postbaccalaureate enrollment. https://nces.ed.gov/programs/ coe

Pomerantz, J., Brown, M., \& Brooks, D. C. (2018). Foundations for a Next Generation Digital

Learning Environment: Faculty, students, and the LMS. ECAR. https://www.educause.edu/ecar/research-publications/foundations-for-anext-generation-digital-learning-environment-faculty-students-and-theIms/introduction

Raths, D. (2018). When learning analytics violate student privacy. Campus Technology. https://campustechnology.com/articles/2018/05/02/whenlearning-analytics-violate-student-privacy.aspx

Saba, F. (2011). Distance education in the United States: Past, present, future Educational Technology, 51(6), 11-18.

Seaman, J., E., Allen, I. E., \& Seaman, J. (2018). Grade increase: Tracking distance education in the United States. Babson Survey Research Group. http://onlinelearningsurvey.com

Simpson, M., \& Anderson, B. (2012). History and heritage in open, flexible and distance education. Journal of Open, Flexible, and Distance Learning, 16(2), 1-10.

Sumner, J. (2000). Serving the system: A critical history of distance education. Open Learning, 15(3), 267-285.

Watters, A. (2014). Beyond the LMS. Hack Education. http://hackeducation. com/2014/09/05/beyond-the-Ims-newcastle-university 